\title{
Indústria 4.0 no Brasil: desafios do segmento automotivo para integração da cadeia
}

\section{de suprimentos}

\author{
Industry 4.0 in Brazil: challenges of the automotive segment for supply chain integration \\ Industria 4.0 en Brasil: desafíos del segmento automotriz para la integración de la cadena de \\ suministro
}

Recebido: 16/06/2021 | Revisado: 21/06/2021 | Aceito: 23/06/2021 | Publicado: 10/07/2021

\author{
Nilza Aparecida dos Santos \\ ORCID: https://orcid.org/0000-0001-9037-0686 \\ Universidade Paulista, Brasil \\ Faculdade de Tecnologia de Cotia, Brasil \\ E-mail: nilza.santos@uol.com.br \\ Sergio Miele Ruggero \\ ORCID: https://orcid.org/0000-0002-2370-2238 \\ Universidade Paulista, Brasil \\ E-mail: smruggero@uol.com.br \\ Marcia Terra da Silva \\ ORCID: https://orcid.org/0000-0002-5314-4978 \\ Universidade Paulista, Brasil \\ E-mail: marcia.terra@uol.com.br
}

\begin{abstract}
Resumo
A Indústria 4.0 oferece oportunidades para a evolução dos processos produtivos por meio do uso intensivo de novas tecnologias que podem transformar o setor industrial, modelos de negócios e competências para agregar valor ao longo das operações da cadeia produtiva. Este artigo busca identificar os desafios do segmento automotivo, no Brasil, para integrar a cadeia de suprimentos, comparando as condições que Autopeças e Montadoras possuem para adoção de tecnologias da Indústria 4.0. Os dados foram coletados por meio de uma pesquisa survey aplicada a profissionais do segmento automotivo. Os resultados indicaram que as autopeças priorizam a permanência no mercado contrariamente às estratégias para a realização de mais investimentos para uso de novas tecnologias, e que as montadoras estão em estágio mais avançado, por possuírem maior capacidade de investimento, acesso às novas tecnologias e outros recursos necessários à transição.
\end{abstract}

Palavras-chave: Conectividade; Interoperabilidade; Investimentos; Tecnologias digitais; Transição.

\begin{abstract}
Industry 4.0 offers opportunities for the evolution of production processes through the intensive use of new technologies which can transform the industrial sector, business models and skills to add value throughout the operations of the production chain. This article seeks to identify the challenges of the automotive segment in Brazil to integrate the supply chain, comparing the conditions that Autoparts and Automakers have for the adoption of 4.0 Industry technologies. Data were collected through a survey research applied to professionals in the automotive sector. The results indicated that Autoparts prioritize the permanence in the market, contrary to strategies to promove more investments to use new technologies, which automakers are at a more advanced stage, as they have greater investment capacity, access to new technologies and other necessary resources to transition.
\end{abstract}

Keywords: Connectivity; Interoperability; Investments; Digital technologies; Transition.

\section{Resumen}

La Industria 4.0 ofrece oportunidades para la evolución de los procesos productivos a través del uso intensivo de nuevas tecnologías que pueden transformar el sector industrial, modelos de negocio y habilidades para agregar valor a lo largo de las operaciones de la cadena productiva. Este artículo busca identificar los desafíos del segmento automotriz en Brasil para integrar la cadena de suministro, comparando las condiciones que tienen Autopartes y Automotrices para la adopción de tecnologías de Industria 4.0. Los datos fueron recolectados a través de una encuesta de investigación aplicada a profesionales del sector automotriz. Los resultados indicaron que las Autopartes priorizan la permanencia en el mercado, contrario a las estrategias de hacer más inversiones para utilizar nuevas tecnologías, y que las automotrices se encuentran en una etapa más avanzada, ya que cuentan con mayor capacidad de inversión, acceso a nuevas tecnologías y otros necesarios. recursos para la transición.

Palabras clave: Conectividad; Interoperabilidad; Inversiones; Tecnologías digitales; Transición. 


\section{Introdução}

A evolução do processo produtivo na Indústria 4.0 possibilita a integração de sistemas ciber físicos, associando o real ao virtual, conectando sistemas digitais, físicos e biológicos, promovendo a produção personalizada em massa e a integração da cadeia de valor (Schwab, 2017). É uma tendência à automação e troca de dados durante o processo de fabricação (Kagermann et al., 2013), que oportuniza a criação de fábricas e modelos produtivos mais inteligentes e eficientes, capazes de alavancar crescimento e desenvolvimento econômico integrando variadas tecnologias (Brettel et al., 2014).

Neste contexto, o uso de novas tecnologias pode aumentar a produtividade, transformar o setor industrial, os modelos de negócios e competências para agregar valor ao longo das operações da cadeia de valor, desde o desenvolvimento e a compra de produtos, até a fabricação, logística e serviços por meio da digitalização e integração vertical de processos.

Dentre essas novas tecnologias, a conectividade considerada como um fator chave pelo World Economic Forum, cria conexões entre dispositivos, sensores, máquinas e softwares, otimizando a comunicação entre os integrantes da cadeia de valor (Büyüközkan \& Göçer, 2018), sendo um dos pré-requisitos necessários para realização da transição para a Indústria 4.0 (Schuh et al., 2017)

No Brasil, estudos da ABIMAQ (2018) apontam que 91\% das empresas não estão conectadas e que o uso de tecnologias para integração com a cadeia de suprimentos se destaca como uma dimensão pouco desenvolvida. Portanto, o uso destas novas tecnologias vai requerer a realização de investimentos para adequação de infraestrutura e qualificação de mão de obra (Lorenz et al, 2016), tendo em vista que a transparência de dados ao longo da cadeia, assim como alterações na cultura, suporte e conhecimento colaborativo são requisitos necessários para transição à Indústria 4.0.

Os desafios para transição à Indústria 4.0 são pertinentes a todos os setores da economia. No tocante aos segmentos industriais no Brasil, o setor automotivo destaca-se pela participação no PIB (Produto Interno Bruto), pela geração de empregos, investimentos em inovação e por significativos encadeamentos em seus processos de produção (Daudt \& Willcox, 2018), assim como a indústria automotiva mundial que tem efeito multiplicador para as empresas que compõem sua cadeia produtiva (European Commission, 2021).

Muitas são as dificuldades que as empresas do segmento automotivo terão que enfrentar para participar da evolução proposta pela Indústria 4.0 e um deles está relacionado a integração da cadeia de suprimentos, visto que esse segmento possui empresas com diferentes condições tecnológicas, capacidade financeira e capital humano, o que pode refletir diretamente no modo como cada componente dessa cadeia pode realizar a transição.

Diante desse cenário, a integração da cadeia de suprimentos no segmento automotivo brasileiro é uma consequência relevante da transição para a Indústria 4.0, porquanto a criação de sinergia entre todos os elos dessa cadeia pode ser necessária para a ruptura de paradigmas em termos de processos produtivos, sobretudo se alavancarem os modelos de negócios.

Levando em conta que a Indústria 4.0 não está restrita ao processo produtivo, da importância da cadeia de suprimentos para competitividade das empresas em termos globais, a questão estudada neste artigo é: Quais os desafios do segmento automotivo, no Brasil, para integrar a cadeia de suprimentos, considerando as tecnologias da Indústria 4.0? O objetivo proposto foi comparar as condições que Autopeças e Montadoras possuem para adoção de tecnologias da Indústria 4.0.

O presente artigo está estruturado em 5 seções: introdução, referencial teórico, metodologia, resultados e discussões, seguidos das considerações finais.

\section{Referencial Teórico}

A Indústria 4.0, parte integrante da quarta revolução industrial, abarca as principais inovações tecnológicas relacionadas a conectividade da automação, controle e tecnologia da informação aplicados a manufatura (Schwab, 2017; Lee et 
al, 2015). Pautada pelo uso crescente de informações e tecnologias de automação no ambiente de fabricação (Davies \& Sharp, 2014) é estruturada pela integração de ativos físicos em sistemas e redes ligados a uma série de tecnologias para criação de valor e propõe a digitalização de ponta-a-ponta da cadeia produtiva (Görçün, 2018).

Para a implantação da Indústria 4.0 são considerados seis etapas, sendo as duas primeiras a informatização e conectividade que são requisitos básicos para sua implementação, seguidas das fases de visibilidade; transparência; capacidade preditiva e adaptabilidade (Schuh et al., 2017). A conectividade estabelece conexões entre dispositivos, sensores, máquinas e softwares e, otimiza a comunicação entre a cadeia de valor e seus stakeholders (Büyüközkan \& Göçer, 2018), assim como a inteligência artificial e a automação flexível são consideradas tecnologias chave para a Indústria 4.0 (World Economic Forum).

Com base no uso destas novas tecnologias a melhoria de produtividade pode ser obtida de forma colaborativa, englobando o trabalho em nível homem-homem, homem máquina e máquina-máquina (Schuh et al. 2014), considerando que a correlação entre a melhoria de produtividade e Indústria 4.0 deve contemplar a alocação de recursos para o uso de novas tecnologias, com a implantação ocorrendo de forma gradual, conforme necessidade de cada empresa (Backhaus \& Nadarajah, 2019).

Em países europeus a indústria automotiva é uma das mais digitalizadas e a inserção de novas tecnologias deve aumentar ainda mais o impacto dessa digitalização (European Commission, 2017a). Embora essas tecnologias ofereçam oportunidades de desenvolvimento de produtos em empresas e instituições de pesquisa, a não adequação aos novos desafios tecnológicos pode atravancar a emergência de produtos, serviços, bem como a inovação.

Em termos de implementação, são necessários requisitos como: a digitalização final de projetos ao longo da cadeia de valor e a integração horizontal que é suportada por tecnologias emergentes como IOT (Internet of Things), redes de sensores sem fio, big data, serviços em nuvem, sistemas embarcados e Internet móvel (Wang et al., 2016a).

O uso dessas tecnologias promove maior conectividade digital nos sistemas homem máquina, resultando na integração vertical e horizontal ao longo da cadeia de valor (Kagermann, 2015) o que compreende, sistemas computacionais e colaborativos compostos por elementos físicos e digitais interconectados, portanto (CPS) ciber físicos (Lee et al., 2015; Colombo et al, 2017), propondo um novo modelo de fabricação na busca de melhoria de processos industriais em todos os elos dessa cadeia (Pilloni, 2018).

Tendo em conta que os CPS retratam o potencial para planejamento, controle e organização dos processos de produção e das cadeias de suprimentos (Hirsch-Kreinsen, 2016), e propõem a interação entre trabalhadores e máquinas (Hermann et al., 2016).

Considerando esses novos modelos de fabricação, surgem as fábricas inteligentes que funcionam de forma integrada em rede e possuem quatro características distintas: a integração vertical dos sistemas de produção inteligentes; a integração horizontal por meio de redes e cadeia global de valor; a engenharia em toda a cadeia de valor e a aceleração através de tecnologias exponenciais (Macdougall, 2014).

O propósito dessas fábricas é atingir um nível mais elevado de automação, operação, eficácia e produtividade (Abbas, 2018). Os principais requisitos são o controle de processos, a obtenção de dados em tempo real e o rastreamento de produtos, moldando um novo padrão de manufatura (Mak et al, 2016). Considerando que um nível mais elevado de dados coletados pode permitir que fabricantes e revendedores otimizem processos ao longo da cadeia produtiva (European Commission, 2017b)

Destaca-se assim que a integração de sistemas é considerada crucial para o sucesso da Indústria 4.0 (Lu, 2017), na medida em que retrata o uso de sistemas de tecnologia da informação (TI) em diferentes níveis hierárquicos das empresas. Assim, otimizando o processo produtivo por meio do monitoramento e do controle de processo em termos operacional e gerencial (Dumitrescu et al., 2015).

De modo mais amplo, a integração entre empresas, interna e externamente, pode ser afetada pela interoperabilidade, 
que se traduz pela capacidade de dois sistemas computacionais diferentes funcionarem em conjunto e conferirem acesso a seus recursos de maneira recíproca (Folmer et al., 2014).

Outro aspecto a considerar refere-se à eficiência operacional, que por um lado é considerada como estrutura à obtenção de vantagem competitiva, mas por outro exige a atualização de tecnologias, equipamentos de produção, gestão de vendas e da cadeia de suprimentos. Consequentemente, empresas que não atenderem esse requisito perdem competitividade em relação aos concorrentes (Porter \& Heppelmann, 2014), considerando que a competitividade está apoiada na redução de custos (Khan \& Turowski, 2016).

A Indústria 4.0 pode ser ampliada para além da área fabril (Brodtmann, 2016), e pode depender da aquisição e compartilhamento de dados em toda a cadeia de suprimentos (Brettel \& Friederichsen, 2014). O grau de complexidade para gerenciamento impõe a necessidade da integração de processos dentro da empresa e ao longo de toda cadeia (Cerra et al., 2014), pois além da condução das suas operações internas, a capacidade de coordenação entre clientes e fornecedores contribui para a eficiência das empresas em seus processos produtivos (Tomas \& Alcantara, 2013).

A cadeia de valor dos produtos, os modelos de negócios e a integração comercial são influenciados pela disseminação e aplicação de tecnologias digitais na indústria. Conforme estudos da CNI (2018) a combinação dessas novas tecnologias pode propiciar ganhos significativos de produtividade e melhorar a competitividade das empresas.

Em face das novas tecnologias e conceitos inerentes à gestão da cadeia de valor, que descentralizam as tomadas de decisões operacionais por meio da criação de fábricas inteligentes, a digitalização nas indústrias tem abordagem mais ampla (Hermann et al., 2016) e por conseguinte interferem na comunicação como uma forma de ruptura dos mercados tradicionais para modelos de negócios digitais que alteram as regras de competição.

Dessa forma, a utilização dos diferentes pilares da Indústria 4.0 oferece maiores oportunidades para os membros da cadeia de valor (Vogel-Heuser \& Hess, 2016), porém impõe colaboração entre fornecedores e distribuidores, fornecedores de tecnologia e infraestrutura e, operadoras de telecomunicações e provedores de serviços de Internet (Davies, 2015).

Logo, empresas que realizam maiores investimentos na aquisição de novas tecnologias, geralmente, são aquelas cujos volumes de produção são capazes de gerar ganhos com economias de escala (Deloitte, 2015), uma vez que para participar da transição à Indústria 4.0 faz-se necessário a adequação dos modelos de negócios (Almada Lobo, 2016).

A descentralização dos processos de negócios tem sido relativamente comum no desenvolvimento da indústria e a evolução das tecnologias de informação com integração das cadeias de suprimentos impulsionam a Indústria 4.0 (Dalenogare et al., 2018; Frank, et al., 2019). Os resultados mais esperados pelo uso dessas tecnologias encontram-se nas áreas de manufatura, gestão industrial, logística e gestão de processos de negócios (Strange \& Zucchella, 2017).

Neste cenário, a conectividade, os recursos e a disponibilidade de informações exigem cada vez mais colaboração entre os participantes da cadeia (Wang \& Onori, 2015) e a digitalização, por sua vez, pode propiciar eficiência na integração, acesso a fabricantes globais, fornecedores de diversas matérias prima e clientes potenciais (Geissbauer \& Schrauf, 2016).

É crescente o número de empresas que têm adotado conceitos e tecnologias da nova revolução industrial para melhorar o desempenho e a produtividade (Rachinger et al., 2018). Uma das principais forças da Indústria 4.0 é o impacto positivo na produtividade das organizações, além da influência no modo de vida da sociedade, como as casas e cidades inteligentes. Nesse processo de evolução tecnológica, a cadeia de suprimentos tem tido um desempenho mais dinâmico para gerenciar o fluxo crescente de dados em sua cadeia de valor na busca de um gerenciamento eficaz (Mouef, 2017).

Assim como, a colaboração na cadeia de suprimentos destaca-se como fator relevante (Nyaga et al., 2010), e pode ser vista como um componente da integração (Wiengarten et al., 2010) que por sua vez pode ser definida como o processo de interação e colaboração interna (Kahn \& Mentzer, 1996). A colaboração e a integração podem ser consideradas sinônimos (Das et al., 2006), entretanto a colaboração pode ser tanto externa entre organizações, quanto interna entre pessoas e 
departamentos (Pagell, 2004).

Do mesmo modo, a familiaridade com novas tecnologias e os benefícios da transformação digital são a cada dia mais compreendidos e os sistemas operacionais tornam-se gradualmente mais complexos (Ras, 2017). A Indústria 4.0 permeia toda a cadeia de valor das organizações e seu escopo pode abranger a cadeia de suprimentos, exigindo novos modelos de negócios.

No tocante a digitalização, a mesma pode proporcionar a abertura de novos mercados, alavancar inovação e ganhos de produtividade, especialmente nas economias em desenvolvimento. Nesse sentido, o apoio governamental com a adoção de programas de incentivo, melhorias em infraestrutura e políticas que desafiem as dificuldades somadas a distribuição dos benefícios da digitalização podem impulsionar inovação e ganhos (IEDI, 2019).

Portanto, um aspecto importante da Indústria 4.0 é a obtenção de dados em tempo real e seu tratamento para obtenção de informações atuais e precisas que possibilitam melhores decisões sobre questões localizadas. Indo além, a troca de informações com agilidade entre subsistemas, permite a colaboração para o enfrentamento de questões que afetam a cadeia de produção como um todo. Destacam-se dessa forma dois fatores importantes para a integração ao longo da cadeia de valor: a obtenção, análise e uso de dados e a conectividade para troca de dados entre empresas da cadeia.

Em relação às barreiras para implementação da Indústria 4.0, as empresas encontram as mais variadas, como: escassez de pesquisa e desenvolvimento, falta de infraestrutura, insuficiência de dados, ausência de cultura digital e confiança nos parceiros de negócios (Wang et al., 2016b). E, para que se possa promover mudanças em estruturas funcionais faz-se necessário gerenciar conhecimento colaborativo e integrar a cadeia de suprimentos com transparência de dados ao longo de toda cadeia (Liao et al., 2017).

Em mercados emergentes, como no caso do Brasil, o uso de novas tecnologias pode oportunizar melhorias aos processos industriais, criando modelos de manufatura inerentes a realidade de cada país. Mas para tanto tem-se a necessidade da realização de investimentos que segundo Lorenz et.al (2016) é a variável capaz de aproximar os pilares da Indústria 4.0 à necessidade de adaptação de infraestrutura e qualificação de mão de obra.

Nesse cenário, pesquisas da Confederação Nacional da Indústria relatam que o nível de investimento no Brasil continua sendo orientado para obtenção de ganhos de produtividade e redução de custos (CNI, 2019) e que muitos são os desafios para que as empresas brasileiras consigam utilizar tecnologias relativas a Indústria 4.0, destacando investimentos em equipamentos que contemplem tecnologias digitais, adaptação de layouts, de processos, relacionamento entre empresas e formas de gerenciamentos ao longo da cadeia produtiva (CNI, 2016).

Os avanços da Indústria 4.0 poderão oportunizar às empresas competitividade e sobrevivência, porém imporão exigências relativas à qualificação da mão de obra que contemplem aspectos técnicos à inovação, gestão do conhecimento e liderança. O desafio da qualificação começa pelos colaboradores que terão que aceitar e entender essas mudanças, pelas empresas que terão que criar ambientes de inovação e condições de desenvolvimento da mão de obra e pela academia que deve estar preparada para oportunizar conhecimento condizente com o processo de transição, que por sua vez deverá ser suportado por políticas públicas capazes de alavancar o desenvolvimento das pessoas (FIRJAN, 2019).

\section{Metodologia}

A realização deste artigo está embasada por uma metodologia de natureza exploratória, quali-quantitativa, que é descrita por Soares Pereira et al. (2018) como um método em que os resultados numéricos são complementados por abordagens qualitativas.

A coleta dos dados primários ocorreu mediante a aplicação de uma pesquisa survey, para profissionais do segmento automotivo, que é empregada para estruturar, ilustrar cenários e investigar categorias que induzem a outras fases da pesquisa (Babbie, 1999), 
Para coleta da pesquisa survey, foi utilizado um formulário para preenchimento via link, enviado por e-mail a 60 gestores de empresas do segmento automotivo, (montadoras e autopeças de pequeno e médio porte), localizadas em São Paulo, Minas Gerais e Rio de Janeiro. As respostas foram recebidas diretamente pela plataforma do Google formulários sem qualquer identificação do respondente ou da empresa e o anonimato foi assegurado aos participantes em todas as etapas do processo de coleta.

A pesquisa contemplou 13 questões com alternativas objetivas e as perguntas foram elaboradas como base em referencial teórico sobre o assunto e o conhecimento dos autores no segmento automotivo. Duas questões foram para qualificação da amostra (tipo de empresa e função) e outras 11 que são descritas na Tabela 1 que identifica também as figuras correspondentes colocadas no capítulo dos resultados, que serão tratadas com maior robustez e analisadas no capítulo discussões.

Tabela 1 - Questões da survey.

\begin{tabular}{l|c}
\hline \multicolumn{1}{c|}{ Questões da survey } & $\begin{array}{c}\text { Número das } \\
\text { figuras } \\
\text { correspondentes }\end{array}$ \\
\hline Qual o nível de conhecimento da sua empresa em relação a indústria 4.0? & 1 \\
\hline $\begin{array}{l}\text { Nas empresas em geral, quais dos tópicos você classifica como sendo impeditivo para } \\
\text { realizar a transição à indústria 4.0? }\end{array}$ & 2 \\
\hline $\begin{array}{l}\text { Quais tópicos você classifica como ganhos a serem obtidos pela transição para a indústria } \\
\text { 4.0? }\end{array}$ & 3 \\
\hline Quais são os gargalos, na sua empresa, para a utilização de novas tecnologias? & 4 \\
\hline $\begin{array}{l}\text { Como a sua empresa pretende qualificar a mão de obra para utilização das tecnologias } \\
\text { relacionadas a indústria 4.0? }\end{array}$ & 5 \\
\hline Qual o nível de conectividade de dados entre sua empresa, fornecedores e clientes? & 6 \\
\hline Qual nível esperado de conectividade de dados entre sua empresa, fornecedores e clientes? & 7 \\
\hline Qual a possibilidade de integração entre máquinas e sistema (Interoperabilidade)? & 8 \\
\hline Qual o nível de utilização, na sua empresa, das tecnologias digitais no processo produtivo? & 11 \\
\hline $\begin{array}{l}\text { Nos últimos 2 anos, qual nível de investimento realizado para a implantação de tecnologias } \\
\text { relativas à indústria 4.0? }\end{array}$ & 11 \\
\hline $\begin{array}{l}\text { Para os próximos 5 anos, qual nível de investimento está sendo previsto para a implantação } \\
\text { de tecnologias relativas à indústria 4.0? }\end{array}$ & \\
\hline
\end{tabular}

Fonte: Autores.

As questões foram realizadas de modo a entender o conhecimento que os participantes da pesquisa possuem em relação à Indústria 4.0, destacando a visão de quais fatores podem impedir a transição à Indústria 4.0 nas empresas de modo geral e quais as expectativas de ganhos (Figuras 1, 2 e 3). As Figuras 4 a 11 relatam a visão dos participantes respectivamente às condições de suas empresas para transição, considerando os gargalos apontados como impeditivos, a qualificação da mão de obra, interoperabilidade interna; conectividade ao longo da cadeia automotiva; o uso de tecnologias da Indústria 4.0 e sobre o nível de investimentos.

$\mathrm{Na}$ seleção dos participantes optou-se por aqueles que exercem funções de liderança na área industrial. O segmento automotivo foi escolhido pela relevância que tem para a economia brasileira pois representa $18 \%$ do PIB Industrial (ANFAVEA, 2020), e as empresas foram selecionadas por fazerem parte cadeia de fornecimento do setor pesquisado.

Dos 60 questionários encaminhados, 51 retornaram respondidos e 9 não justificaram a ausência de envio. A amostra coletada foi composta por $65 \%$ de empresas de autopeças, $25 \%$ de empresas montadoras e $10 \%$ de empresas metalúrgicas e os respondentes ocupam funções de liderança (diretores, gerentes e supervisores). 
Considerando os objetivos propostos para este artigo foram utilizadas as respostas de autopeças e montadoras, e as empresas metalúrgicas foram excluídas da amostragem por serem fornecedoras de diversos setores, não somente automobilístico. Os dados foram estratificados dos 51 questionários recebidos, contemplando respostas de 33 participantes de autopeças e 13 de montadoras, perfazendo 46 questionários respondidos. Com essa nova composição a amostra é representada por $72 \%$ de empresas de autopeças e $28 \%$ de empresas montadoras no universo das empresas pesquisadas. Os dados secundários foram apurados por análise documental e das referências bibliográficas.

A validade da pesquisa fica assegurada pela descrição e entendimento dos aspectos relativos à integração e colaboração ao longo da cadeia automotiva. A aderência dos dados coletados se dá pela construção da realidade das empresas participantes e pela visão dos respondentes. Considerando ainda que todos os líderes selecionados têm experiência profissional na área industrial do segmento pesquisado e que as empresas são integrantes da cadeia automotiva brasileira.

\section{Resultados}

Os resultados obtidos são apresentados por meio das figuras a seguir. A Figura 1 aponta o nível de conhecimento sobre Indústria 4.0 considerado pelos gestores das empresas pesquisadas, em que mais que uma das alternativas poderia ser assinalada.

Figura 1 - Conhecimento dos gestores das empresas sobre Indústria 4.0.

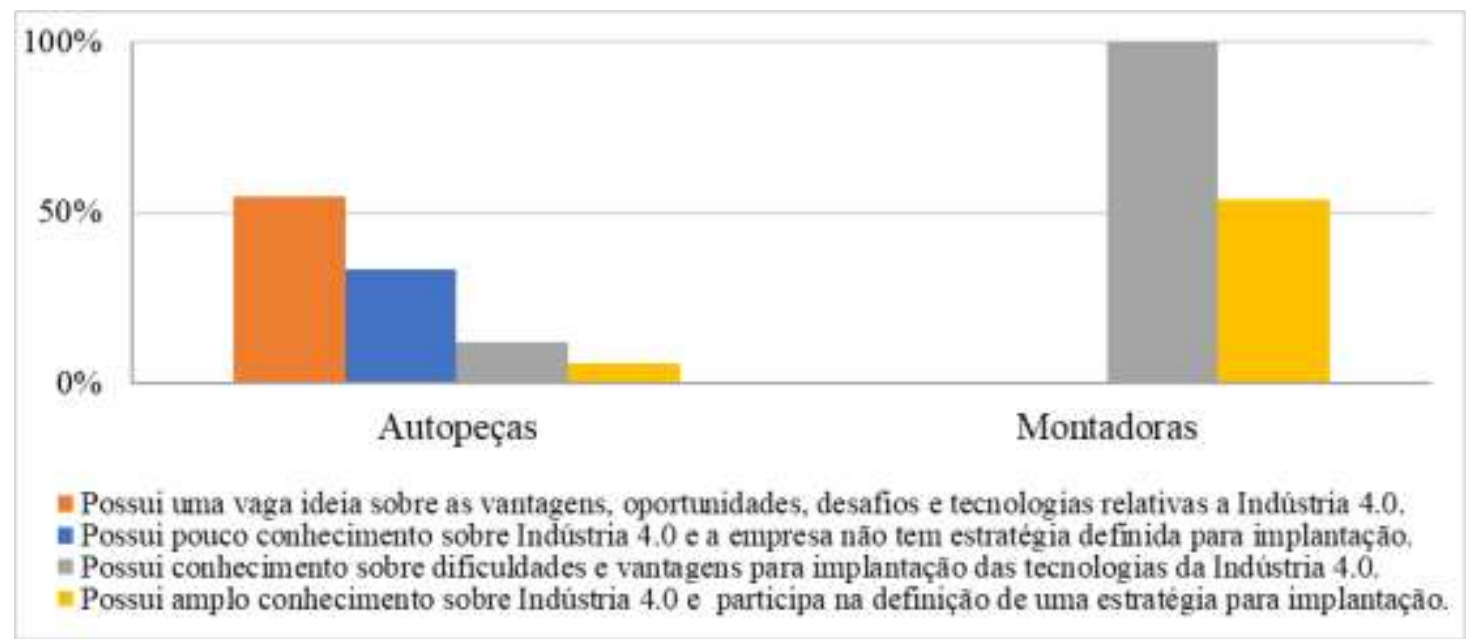

Fonte: Autores.

Como pode-se observar na Figura 1, o nível de conhecimento apontado pelos respondentes das empresas montadoras é superior ao das autopeças, visto que $100 \%$ dos participantes das montadoras indicam ter conhecimento sobre dificuldades e vantagens para implantação das tecnologias da Indústria 4.0 contra $12 \%$ das autopeças. Em relação ao nível mais amplo de conhecimento a situação também reforça as diferenças em termos de conhecimento sobre o tema, visto que 54\% das montadoras apontam ter amplo conhecimento enquanto apenas $6 \%$ das autopeças sinalizam esse nível.

Os fatores apontados como impedimentos para a transição à Indústria 4,0 são evidenciados na Figura 2, considerando a visão dos participantes da pesquisa em relação às empresas em geral. 
Figura 2 - Impedimentos para a utilização de novas tecnologias para as empresas em geral.

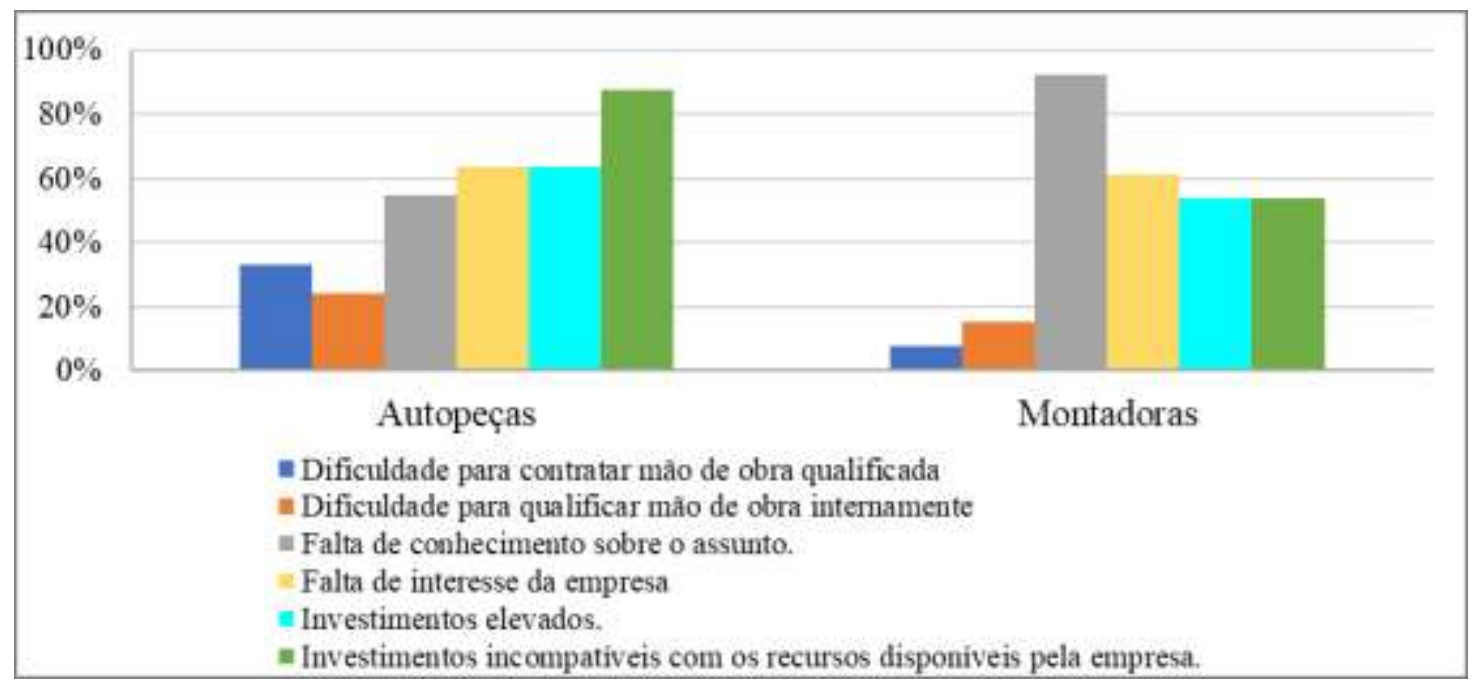

Fonte: Autores.

No tocante aos fatores que podem impedir a transição à Indústria 4.0 (Figura 2) todos os quesitos foram mencionados tanto por autopeças quanto por montadoras. Entretanto, enquanto as autopeças sinalizaram investimentos incompatíveis como o maior entrave, as montadoras destacam a falta de conhecimento das empresas de modo geral, aspecto esse já evidenciado na Figura 1 que apresenta o baixo conhecimento das empresas de autopeças.

A realização à transição para Indústria 4.0 também pode ser vista como uma oportunidade para obtenção de ganhos, as expectativas esperadas pelos participantes das empresas pesquisadas são evidenciadas na Figura 3 a seguir.

Figura 3 - Expectativas de ganhos pela transição para a indústria 4.0.

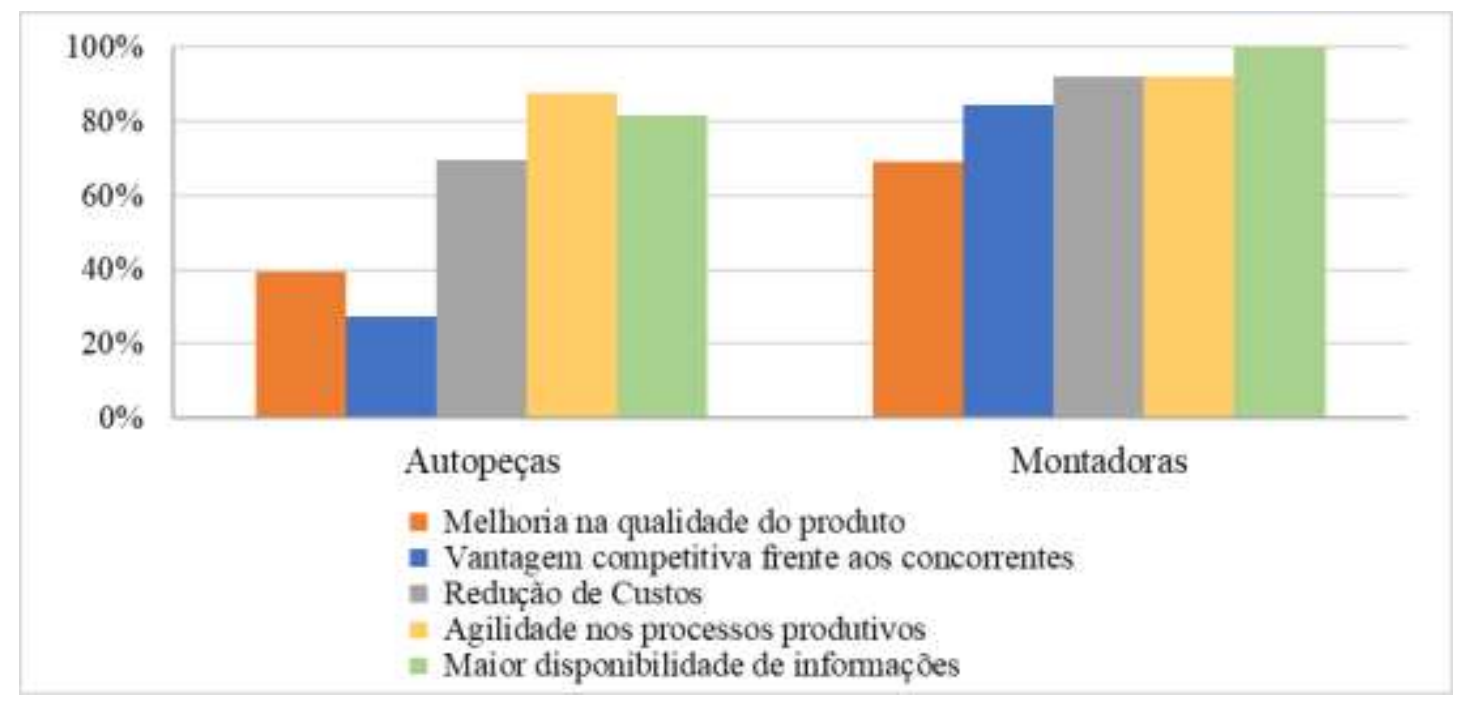

Fonte: Autores.

No que se refere aos ganhos esperados com a realização da transição à Indústria 4.0 (Figura 3), os respondentes indicaram ter as mesmas expectativas. Entretanto para as montadoras uma maior disponibilidade de informação é o ganho mais esperado e para as autopeças a agilidade nos processos produtivos. Uma observação relacionada a obtenção de vantagem competitiva merece destaque pois as autopeças não vislumbram esse ganho com a mesma ênfase das montadoras. 
Research, Society and Development, v. 10, n. 8, e18110817251, 2021

(CC BY 4.0) | ISSN 2525-3409 | DOI: http://dx.doi.org/10.33448/rsd-v10i8.17251

As dificuldades apontadas pelos respondentes da pesquisa em relação aos gargalos que suas respectivas empresas apresentam são evidenciadas na Figura 4.

Figura 4 - Gargalos para o uso de novas tecnologias para as empresas pesquisadas.

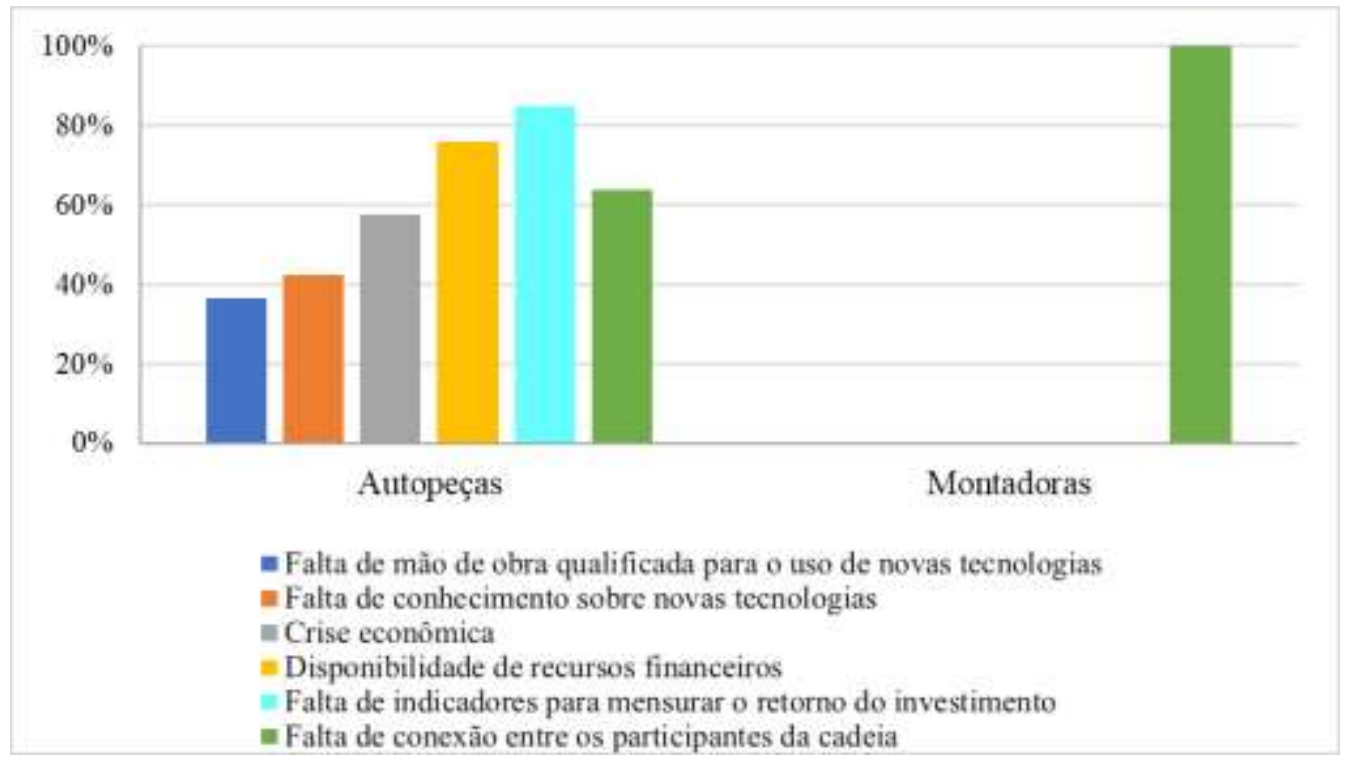

Fonte: Autores.

Conforme pode-se observar na Figura 4, a visão em relação aos entraves para a realização da transição difere de forma significativa nas empresas pesquisadas. Enquanto as autopeças enxergam como obstáculos internos basicamente o que apontaram como sendo impedimentos para todas as empresas (Figura 2), o olhar dos respondentes das montadoras volta-se apenas para a falta de conexão entre os participantes da cadeia.

Aspectos relativos à qualificação da mão de obra para uso de tecnologias pertinentes a Indústria 4.0 são mostrados na Figura 5 .

Figura 5 - Como as empresas pesquisadas pretendem qualificar a mão de obra para utilização das tecnologias da indústria 4.0.

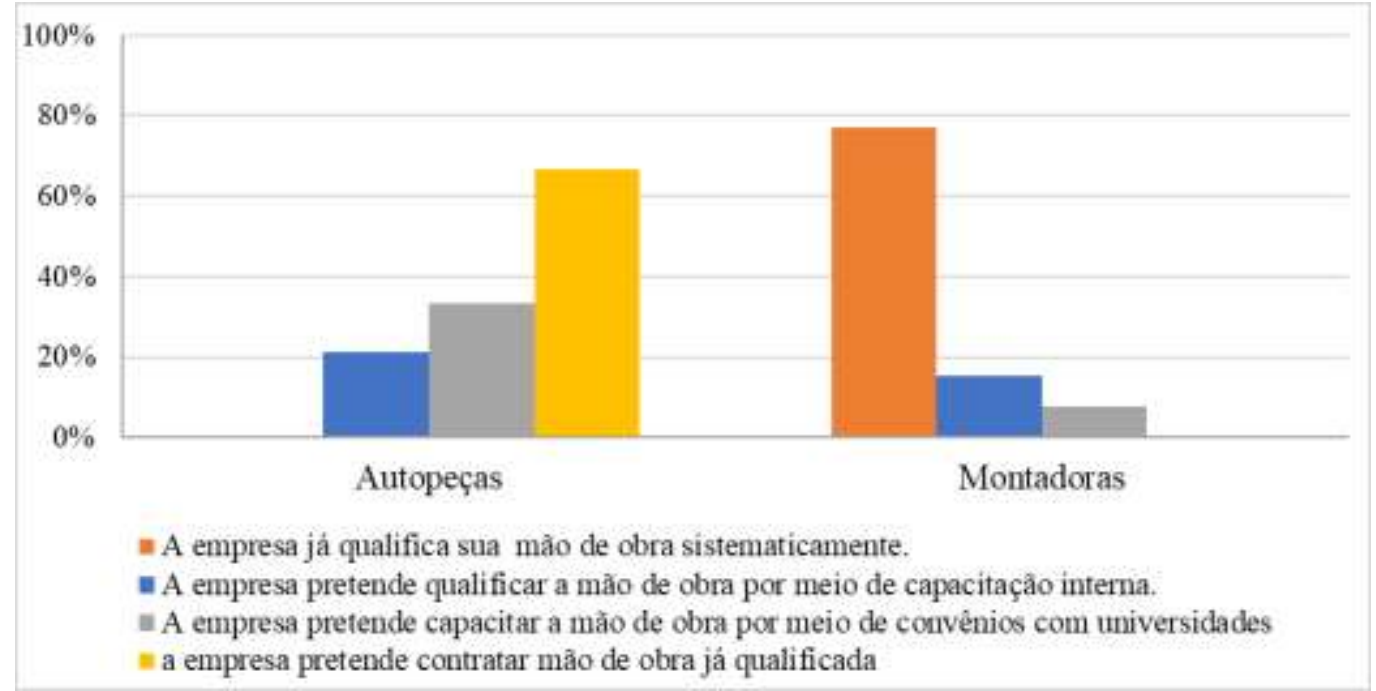

Fonte: Autores. 
Os dados sobre o modo como as empresas pretendem qualificar e qualificam a mão de obra para o uso de novas tecnologias também difere entre as empresas participantes da amostra. Enquanto as autopeças indicam que pretendem contratar mão de obra já qualificada, as montadoras apontam para qualificação sistemática dos seus colaboradores.

A conexão entre os participantes da cadeia, destacada de modo importante por montadoras (Figura 4), tem seus níveis relatados na Figura 6 que apresenta os níveis de conectividade de dados entre as empresas pesquisadas, fornecedores e clientes.

Figura 6 - Nível atual de conectividade de dados entre a empresa, fornecedores e clientes.

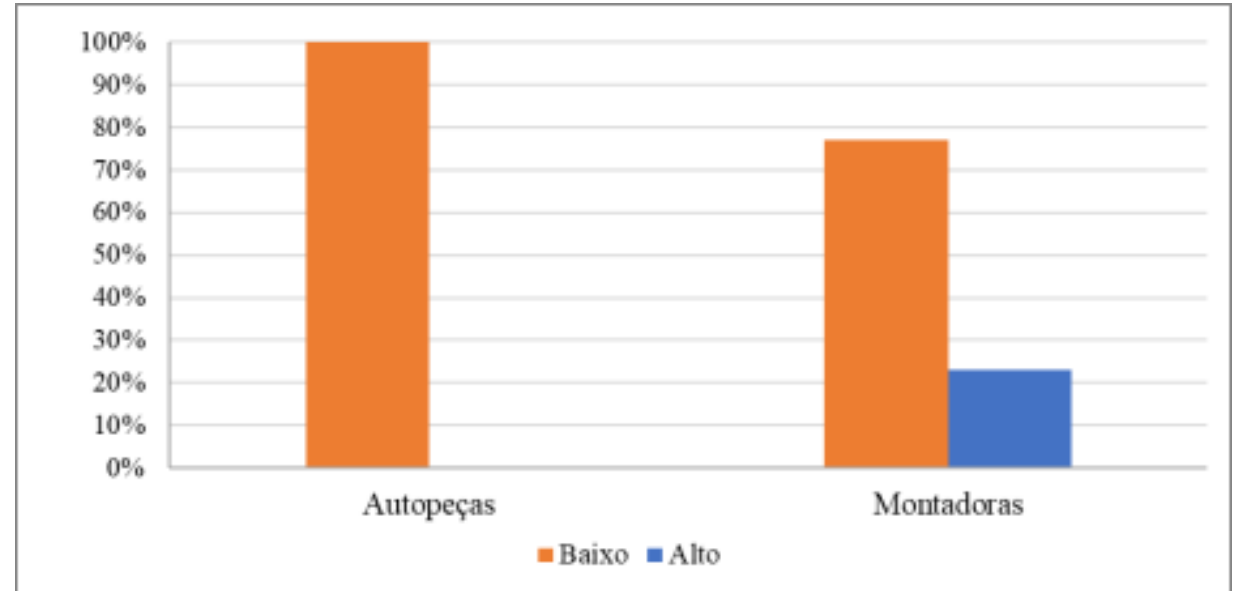

Fonte: Autores.

O nível de conectividade de dados entre as empresas pesquisadas, seus fornecedores e clientes se apresenta em nível baixo para $100 \%$ das autopeças. Nas montadoras $77 \%$ indicam ter nível baixo de conexão e $23 \%$ nível alto, possivelmente refere-se à conectividade estabelecida com seus clientes, já que a totalidade das empresas de autopeças pesquisadas sinalizaram um nível baixo de conexão.

Ainda no tocante a conectividade, indagou-se qual a expectativa de conexão entre as empresas investigadas, seus fornecedores e clientes. Os resultados obtidos são mostrados na Figura 7.

Figura 7 - Nível esperado de conectividade de dados entre empresa, fornecedores e clientes.

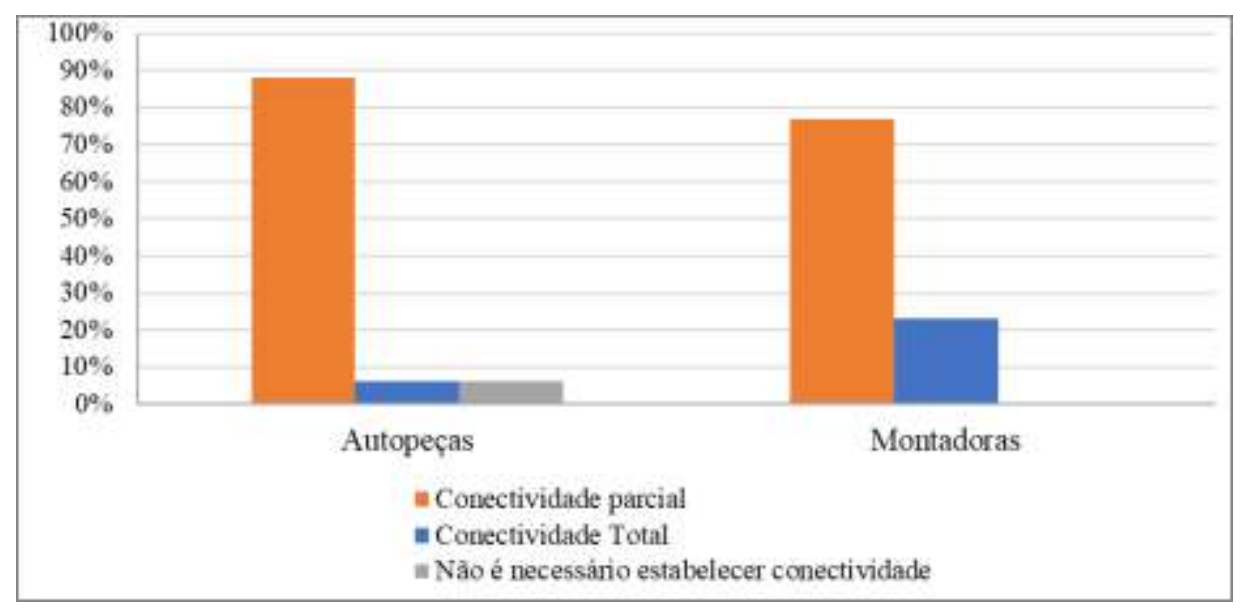

Fonte: Autores. 
A conectividade de dados esperada (Figura7) pelas montadoras coincide com o cenário atual (Figura 6) no qual 23\% das montadoras esperam que o nível seja elevado. Entretanto essa disposição não aparece nas repostas das autopeças, visto que apenas 6\% dessas empresas almejam um nível elevado de conexão com os outros integrantes da cadeia. Tal situação pode ser explicada considerando os gargalos indicados na Figura 4, nos quais as autopeças demonstram enfrentar dificuldades bem diferentes das montadoras.

A interoperabilidade que retrata a integração entre máquinas e sistema é apontada na Figura 8.

Figura 8 - Possibilidade de integração entre máquinas e sistema (Interoperabilidade).

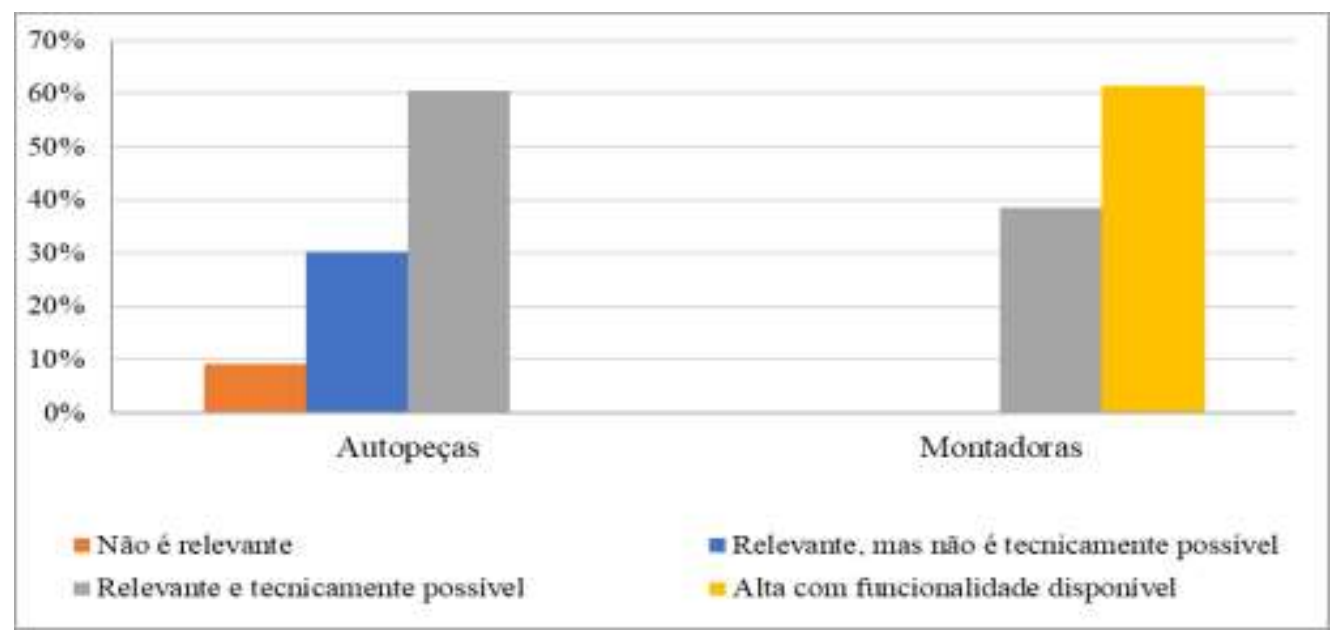

Fonte: Autores.

$\mathrm{Na}$ análise das respostas percebe-se que a relevância e possibilidade de interoperabilidade é apontada por autopeças e montadoras, entretanto a disponibilidade de funcionalidade relatada por $62 \%$ das montadoras não aparece para as autopeças pesquisadas.

Complementando o relato do cenário das empresas pesquisadas na comparação das Figuras 9 e 10 que tratam do uso de tecnologias referentes a Indústria 4.0 por autopeças e montadoras respectivamente, percebe-se que as diferenças entre as referidas empresas são significativas, pois enquanto o nível de utilização das autopeças concentra-se entre baixo e nulo, nas montadoras fica entre médio e alto, destacando a defasagem tecnológica entre os dois elos da cadeia automotiva. 
Research, Society and Development, v. 10, n. 8, e18110817251, 2021

(CC BY 4.0) | ISSN 2525-3409 | DOI: http://dx.doi.org/10.33448/rsd-v10i8.17251

Figura 9 - Nível de utilização de tecnologias pelas empresas de Autopeças.

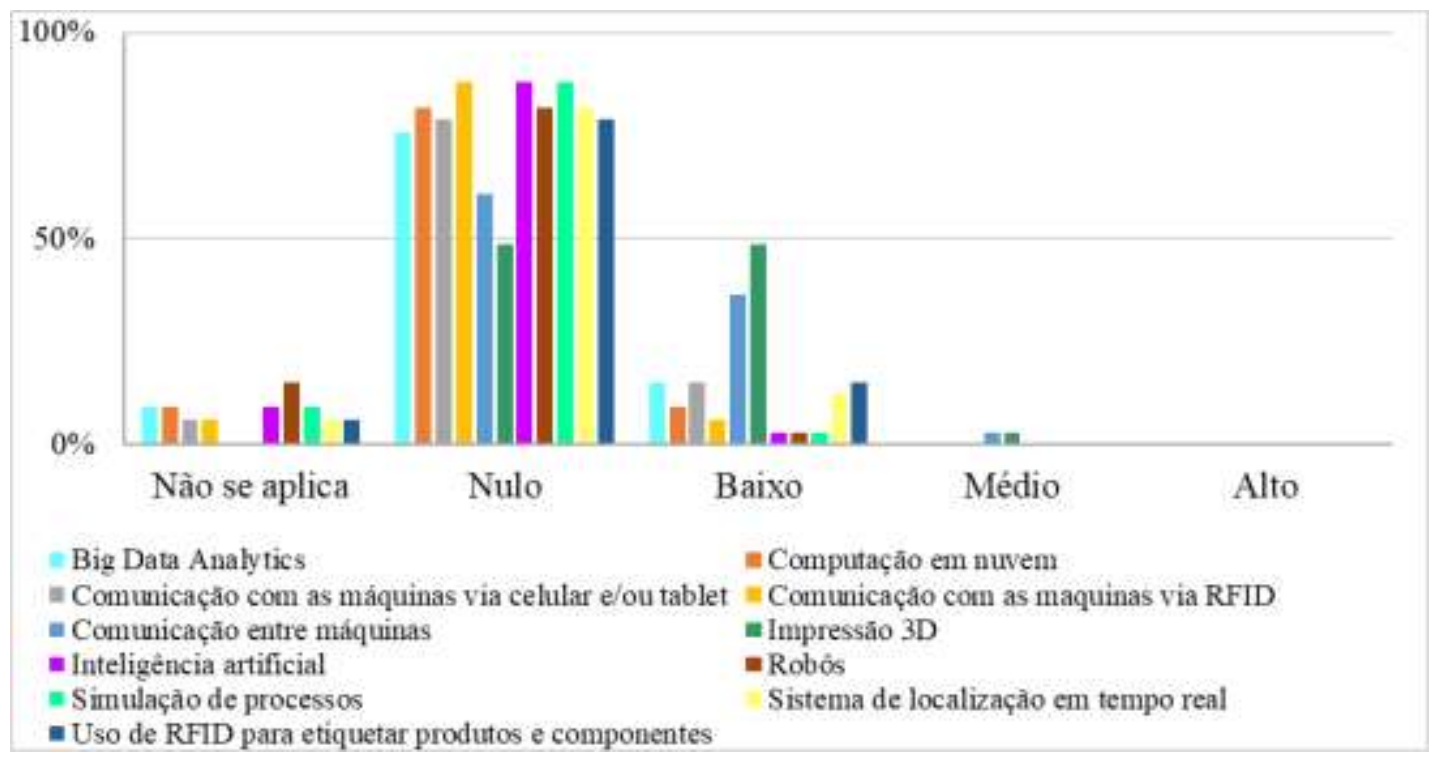

Fonte: Autores.

Figura 10 - Nível de utilização de tecnologias pelas empresas Montadoras.

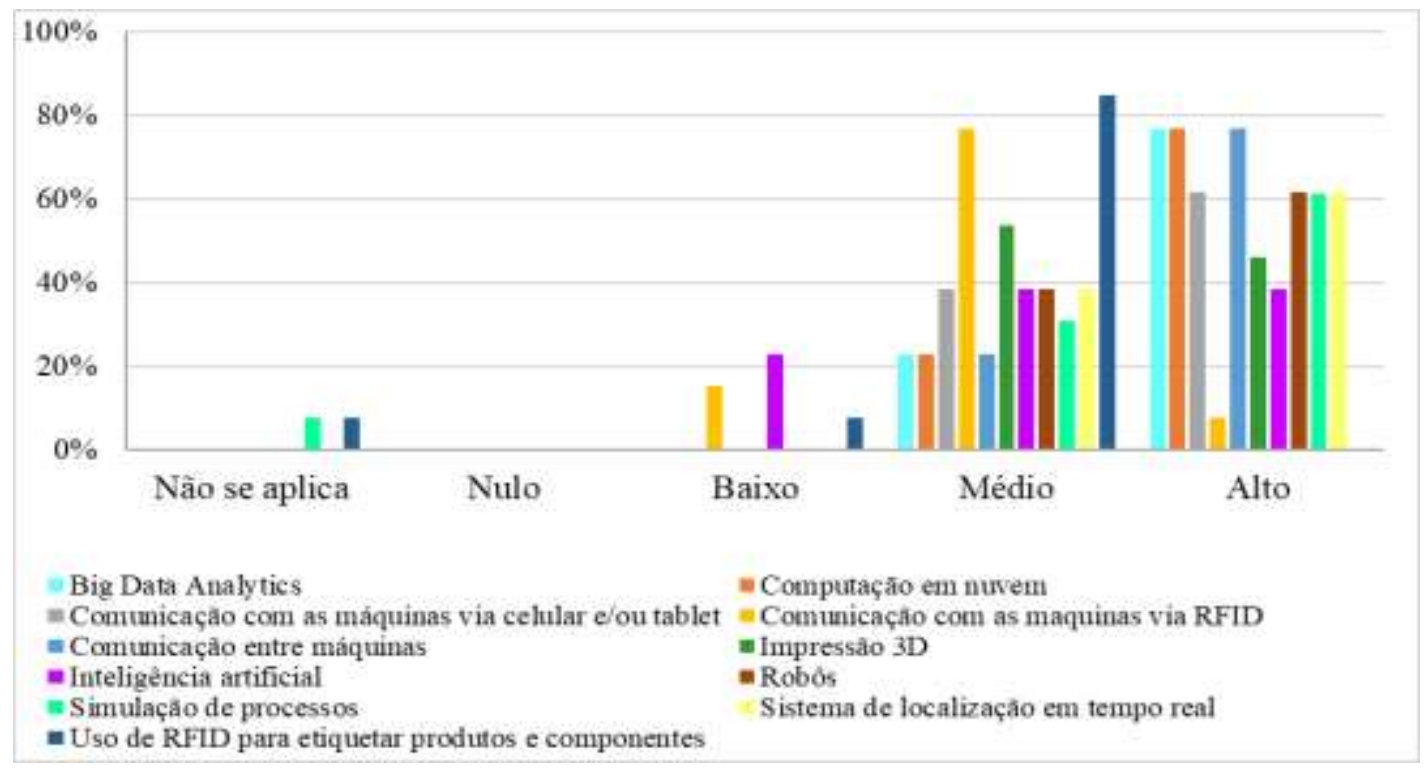

Fonte: Autores.

Observa-se na Figura 10 que as montadoras denotam níveis de utilização de tecnologia entre médio e alto. Tecnologias como comunicação entre máquinas, big data analytics e computação tem indicação de uso por $77 \%$ dos participantes dessas empresas. A desigualdade entre as empresas, apurada pela pesquisa, podem ser explicadas em parte pelo nível de investimento realizado nos últimos 2 anos e a realizar nos próximos 5 anos (Figura 11), considerando que a pesquisa foi realizada entre os meses de dezembro de 2019 e janeiro de 2020. 
Figura 11 - Nível de investimentos.

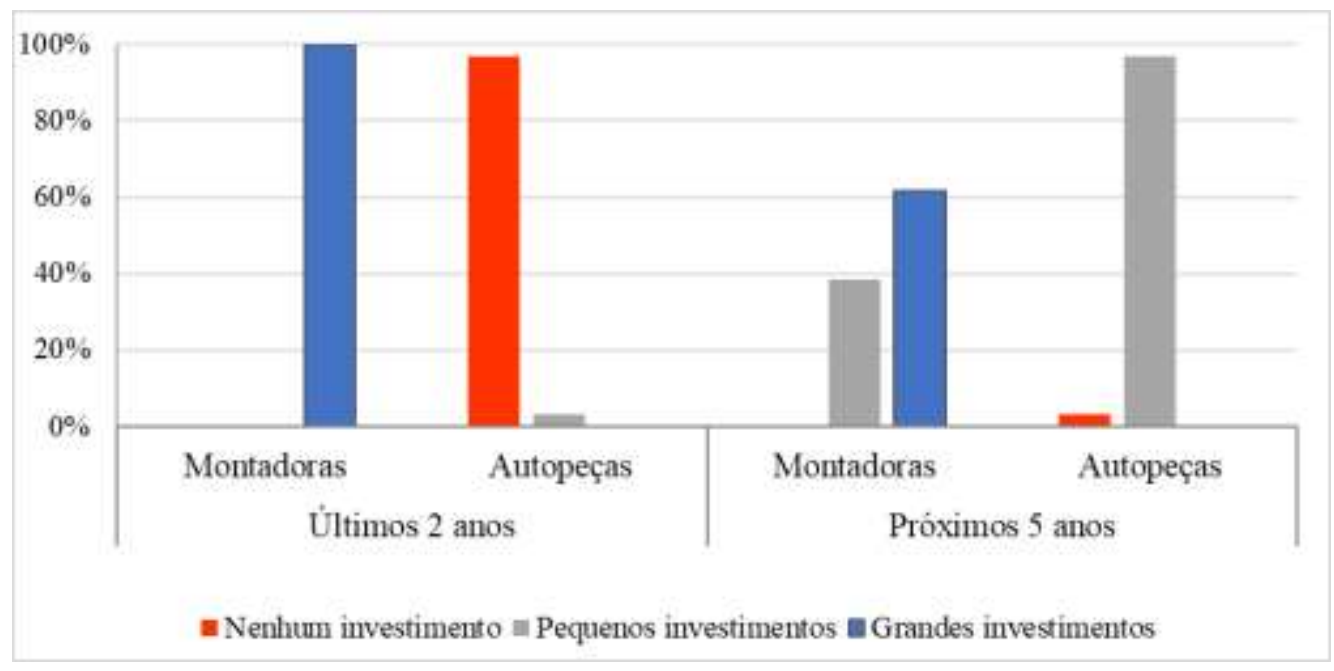

Fonte: Autores.

Em relação aos investimentos em tecnologias relativas à Indústria 4.0, nos últimos dois anos enquanto a totalidade das montadoras pesquisadas sinalizaram grandes investimentos, as autopeças praticamente não realizaram investimentos para essas novas tecnologias. Para os próximos 5 anos as autopeças pretendem realizar pequenos investimentos e as montadoras sinalizam para continuidade na realização de investimentos.

Tendo em vista as diferenças entre montadoras e autopeças apontados, os resultados apresentados são discutidos de forma mais acentuada na seção a seguir.

\section{Discussão}

Considerando que a integração e automação dos processos industriais demandam entendimento entre os diversos atores que compõem a cadeia de valor (Erol et al., 2016), assim como a interoperabilidade nessa cadeia permite expandir as redes de negócios (Ibarra et al., 2018). As dificuldades enfrentadas pelas autopeças no uso de tecnologias da Indústria 4.0, apesar do melhor cenário apresentado pelas montadoras, dificultam a integração e colaboração da cadeia automotiva como um todo.

As tecnologias disruptivas alavancam a Indústria 4.0 com a ampliação do volume de dados, conectividade, digitalização e novos modelos de interação entre homem máquina, (Baur \& Wee, 2015), e as empresas necessitam adequar seu modelo de negócios para participar dessa transformação (Almada-Lobo, 2016), embora muitos outros fatores sejam necessários, o conhecimento sobre Indústria 4.0 é condição basilar ao processo de transição à Indústria 4.0.

Em relação aos impedimentos para o uso de novas tecnologias, pelas empresas em geral, montadoras e autopeças elencaram os mesmos entraves. Entretanto, para as autopeças o nível de investimentos incompatível é mais destacado, enquanto as montadoras ressaltaram a falta de conhecimento sobre o tema Indústria 4.0, corroborando com pesquisas da CNI (2016) que apontam para o baixo conhecimento que os usuários das indústrias, de modo geral, possuem sobre as tecnologias digitais e seus benefícios.

Apesar dos impedimentos apontados, os participantes da pesquisa também concebem possibilidades de ganhos com a realização da transição à Indústria 4.0. Embora os ganhos mais esperados para as autopeças tenha sido agilidade nos processos produtivos e para montadoras maior disponibilidade de informação, a redução de custos que está diretamente ligada a ganhos de produtividade também é evidenciada, corroborando com as afirmações de Rüßmann et al. (2015) em que as tecnologias da 
Indústria 4.0 permitem a junção e análise de dados entre máquinas, agilização e flexibilização, tornando os processos mais eficientes.

No que concerne aos gargalos enfrentados pelas respectivas empresas dos respondentes, encontra-se um cenário diferenciado, enquanto para as montadoras o único gargalo é a falta de conexão entre os participantes da cadeia para uso de novas tecnologias, as autopeças, além desse, citam diversos outros. A situação das autopeças tem amparo nas colocações de Wang et al., (2016) em que as empresas encontram barreiras para implantação da Indústria 4.0 relacionadas a escassez de pesquisa e desenvolvimento, falta de infraestrutura, insuficiência de dados, ausência de cultura digital e confiança nos parceiros de negócios.

Outra questão que também sinaliza diferenças nas respostas das empresas pesquisadas remete-se a qualificação da mão de obra para o uso de novas tecnologias, enquanto as autopeças indicam que pretendem contratar mão de obra já qualificada, montadoras descartam essa possibilidade e colocam que qualificam seus colaboradores de forma contínua. A posição das montadoras está de acordo com estudos da FIRJAN (2019) em que o papel das empresas no processo de transição é criar condições para que as pessoas possam desenvolver-se. Entretanto percebeu-se que as autopeças ainda não possuem o mesmo patamar de condições para qualificação de seus colaboradores.

A situação apontada pelos respondentes das empresas de autopeças em relação aos inúmeros gargalos, falta de conhecimento e qualificação da mão de obra vai ao encontro com pesquisas da CNI (2016), que sinaliza que nem todos os segmentos industriais conseguem avançar no mesmo ritmo em direção ao uso de novas tecnologias. De maneira análoga, dados disponibilizados pelo MDIC - Ministério da Economia, Indústria, Comércio e Serviços em 2019 apontam que inúmeras das empresas de menor porte do segmento automotivo possuem dívidas, inclusive tributárias, aumentando os obstáculos à obtenção de financiamento de bancos privados e públicos, tanto para investimentos, quanto para capital de giro.

Os respondentes das empresas pesquisadas indicaram que o nível de conectividade de dados que se estabelece entre as empresas, fornecedores e clientes é baixo, indo ao encontro do estabelecido por pesquisa da ABIMAQ (2018) na qual 91\% das empresas brasileiras não estão conectadas. Embora as montadoras e autopeças pesquisadas sinalizaram para um nível baixo de conectividade, $23 \%$ dos entrevistados das montadoras apontaram para um alto nível de conectividade.

Outra situação colocada refere-se ao nível de conectividade esperado, e nesse caso montadoras e autopeças sinalizaram para um nível parcial. Destaca-se aqui que para 23\% das montadoras a expectativa de conectividade é total, o que corresponde a parcela de montadoras que alegaram já possuírem um nível alto de conectividade. As montadoras mais uma vez mostram ter maior proximidade às premissas da Indústria 4.0, visto que o World Economic Forum classifica a conectividade como tecnologia chave para a transição.

Cabe ressaltar que a falta de conexão destacada por $100 \%$ das montadoras e mencionada por $64 \%$ autopeças, configura-se como um impedimento importante ao uso de novas tecnologias, dificultando a integração de empresas do segmento automotivo ao longo da cadeia produtiva. A conexão entre clientes e fornecedores comunica e integra componentes ao longo da cadeia (PWC, 2016) e pode ser apontada como agente transformador das cadeias de valor da indústria e de modelos de negócios (Zhong et al., 2017).

No sentido de estabelecer a conectividade esperada, que pode permitir maior integração ao longo da cadeia do segmento automotivo, o investimento em novas tecnologias tem papel importante. As diferenças encontradas entre montadoras e autopeças em relação a essas tecnologias, em parte podem ser explicadas, pelo baixo nível de investimentos realizados e a realizar pelas autopeças.

No tocante ao uso de tecnologias da Indústria 4.0, a presente pesquisa também evidencia uma defasagem tecnológica maior para as autopeças, visto que para elas o uso dessas tecnologias é inexistente, enquanto para montadoras o nível de utilização oscila entre alto e médio. Considerando que a evolução das tecnologias de informação e sua integração às cadeias de 
suprimentos resultam na Indústria 4.0 conforme Dalenogare et al. (2018) e Frank et al. (2019) e que essas são mais dinâmicas para gerenciamento do fluxo de dados (Mouef, 2017), as diferenças apuradas entre montadoras e autopeças dificultam ainda mais o processo de integração ao longo da cadeia automotiva brasileira.

Considerando o colocado por Schuh et al. (2017) que afirmam ser necessário o atendimento dos seguintes estágios de maturidade: Informatização, Conectividade, Visibilidade, Transparência, Capacidade Preditiva e Adaptabilidade, para que as empresas possam realizar a transição para a Indústria 4.0, pode-se dizer que as dificuldades apontadas para o uso de novas tecnologias também são encontradas em empresas de outros países como por exemplo a Alemanha, que de acordo com dados divulgados pela VDI - Associação de Engenheiros Brasil-Alemanha -, ainda estão em fase de implantação do estágio de informatização e conectividade.

Em mercados emergentes, como no caso do Brasil, o uso de novas tecnologias pode oportunizar melhorias aos processos industriais, criando modelos de manufatura inerentes a realidade de cada país. Mas para tanto tem-se a necessidade da realização de investimentos que segundo Lorenz et.al (2016) é a variável capaz de aproximar os pilares da Indústria 4.0 à necessidade de adaptação de infraestrutura e qualificação de mão de obra.

\section{Conclusão}

A competição nos negócios tem gerado inovações tecnológicas e essa mudança influencia os modelos e as estruturas operacionais estratégicas, porém muitos são os desafios. Fica evidente, a partir do pressuposto teórico, que a pesquisa proposta encontrou amparo e subsídio na bibliografia.

Destaca-se pelo relatado nesta pesquisa empírica que montadoras e autopeças apresentam condições díspares para o uso de novas tecnologias conforme Figuras 9 e 10 o que dificulta a integração ao longo da cadeia. Ainda no que tange a obtenção dos resultados para esta amostra, a desigualdade de condições entre montadoras e autopeças se apresenta de forma perceptível, tendo em conta que a análise dos dados da pesquisa revelou que a defasagem tecnológica é maior para as autopeças, porquanto para essas empresas prevalece a inexistência dessas tecnologias, enquanto para as montadoras impera um nível maior de utilização.

Assim, na comparação entre montadoras e autopeças, verifica-se que realidade é diferente em relação as dificuldades para o uso de novas tecnologias e consequentemente para promover a integração ao longo da cadeia automotiva. Neste contexto, apesar da interdependência entre autopeças e montadoras e, os resultados indicaram que as autopeças, priorizam a permanência no mercado contrariamente às estratégias para a realização de mais investimentos para uso de novas tecnologias e que as montadoras estão em estágio mais avançado, por possuírem maior capacidade de investimento, acesso a novas tecnologias e outros recursos necessários à transição.

Cabe destacar que estudos da FIRJAN (2016) apontam que, no Brasil, o segmento automotivo é o que se encontra em estágio mais avançado para realização da transição à Indústria 4.0 e que o uso dessas novas tecnologias pode levar a indústria automotiva a ter maior competitividade. Por outro lado, em consonância com os resultados relatados nesse artigo, pesquisas da CNI (2019), colocam que nem todos os segmentos industriais conseguem avançar no mesmo ritmo.

Dessa forma, na identificação e análise dos resultados relatados por autopeças e montadoras que compõem o segmento automotivo brasileiro, verificou-se que muitos são os desafios para promover a integração da cadeia de suprimentos considerando o uso de tecnologias da Indústria 4.0, especialmente para as autopeças cujas condições para adoção de novas tecnologias são diversas a conjuntura das montadoras.

Contudo, apesar das diferenças apontadas, conforme mencionado em texto do IEDI (2019) há que se considerar que o sistema industrial, possui conexões que atravessam diversas cadeias, e que quando um vetor promove progresso tecnológico, 
oportuniza estratégias estruturadas em direção à Indústria 4.0, concebendo assim caminhos para estabilidade e desenvolvimento do país, ancorados pelo crescimento da produção.

Diante do exposto, a luz da teoria pesquisada e da apuração e análise dos resultados apresentados, as principais contribuições desse artigo foram: 1) entender aspectos relacionados ao uso de tecnologias da Indústria 4.0, no Brasil, especialmente no segmento automotivo; 2) identificar as dificuldades encontradas por montadoras e autopeças para promover a integração ao longo da cadeia de suprimentos levando-se em conta suas especificidades; 3) enfatizar a importância da necessidade de integração dos elos da cadeia de suprimentos do segmento automotivo.

O presente artigo foi realizado, considerando toda cautela na interpretação, análise e apresentação dos dados para garantir os resultados apresentados, todavia não podem ser generalizados para o universo de empresas, pela limitação do tamanho da amostra e porque outras pesquisas, em outros tempos, ou segmentos podem apresentar resultados distintos.

Dada a relevância do tema, como proposta de estudos futuros recomenda-se identificar quais as estratégias de empresas do segmento automotivo para integração ao longo da cadeia de suprimentos.

\section{Agradecimentos}

"O presente trabalho foi realizado com apoio da Coordenação de Aperfeiçoamento de Pessoal de Nível Superior Brasil (CAPES) - Código de Financiamento 001".

\section{Referências}

Abbas, S. A. (2018). Entrepreneurship, and information technology businesses in economic crisis. Entrepreneurship and Sustainability Issues.

ABIMAQ - Associação Brasileira de Máquinas e Equipamentos. (2018). Full General Report. http://abimaq.org.br/comunicacoes/ 2018/ projetos.

Almada-Lobo, FRANCISCO. (2016). The Industry 4.0 revolution and the future of manufacturing execution systems (MES). Journal of innovation management 3.4 .

ANFAVEA - Associação Nacional dos Fabricantes de Veículos Automotores. (2020). Anuário da Indústria Automobilística Brasileira, São Paulo.

Babbie, Earl. (1999). Métodos de pesquisas de survey. Belo Horizonte: UFMG.

Backhaus, S., \& Nadarajah, D. (2019). Investigating the Relationship between Industry 4.0 and Productivity: A Conceptual Framework for Malaysian. Manufacturing Firms. Procedia Computer Science, (161), 696-706.

Baur, Cornelius, \& Wee, Dominik. (2015). Manufacturing's next act. McKinsey Quarterly.

Brettel, M. \& Friederichsen, N. (2014). How Virtualization, Decentralization and Network Building Change the Manufacturing Landscape: An Industry 4.0 Perspective. International Journal of Mechanical, Aerospace, Industrial, Mechatronic and Manufacturing Engineering, 8,1, 37-44.

Brodtmann, T. (2016). Why Industry 4.0 is not just about industry. https://www.euractiv.com/section/digital/opinion.

Büyüközkan, G., \& Göçer, F. (2018). Digital supply chain: literature review and a proposed framework for future research. Comput. Ind. 97, $157-177$.

Cerra, A. L., Maia, J. L., Alves Filho, A. G., \& Nogueira, E. (2014). Cadeias de suprimentos de montadoras dos setores automobilístico e de linha branca Uma análise comparativa por meio de estudos de caso. Gestão da Produção, 21(3), 635-647.

CNI - Confederação Nacional da Indústria. (2016). Industry 4.0. Special poll. Brasília, n. 66, may.

CNI - Confederação Nacional da Indústria. (2018). Industry 2027 Risks and Opportunities for Brazil in the face of disruptive innovations.

CNI - Confederação Nacional da Indústria. (2019). Indicadores Industriais. http://www.portaldaindustria.com.br/estatisticas/ indicadores-industriais.

Colombo, A. W., Karnouskos, S., Kaynak, O., Shi, Y., \& Yin, S. (2017) Industrial cyber-physical systems: A backbone of the fourth industrial revolution. IEEE Industrial Electronics Magazine, 11, 1.

Dalenogare, L. S., Benitez, G. B., Ayala, N. F. \& Frank, A. G. (2018). A contribuição esperada das tecnologias da Indústria 4.0 para o desempenho industrial. International Journal of Production Economics. 204, 383-94.

Das, A., Narasimhan, R. \& TallurI, S. (2006). Supplier integration - finding an optimal configuration. Journal of Operations Management, $24,5,563-82$. 
Daudt, G. M., Willcox, L. D. (2018). Indústria automotiva = Automotive industry. In: Puga, F. P., Castro, L. B. de (Org.). Visão 2035 Brasil, país desenvolvido: agendas setoriais para alcance da meta. Rio de Janeiro: Banco Nacional de Desenvolvimento Econômico e Social, 1, $183-208$.

Davies, A, \& Sharp, D. R. (2014). Strategic Facilities Management. Case studies, International Workplace, Cambridge, Report.

Davies, R. (2015). Industry 4.0: digitalisation for productivity and growth. European Parliamentary Research Service. www.europarl.europa.eu/RegData/etudes/BRIE/2015/568337/EPRS_BRI(2015)568337_EN.pdf .

DELOITTE (2015). Industry 4.0 challenges and solutions for the digital transformation and use of exponential technologies. www2.deloitte.com/content/dam/Deloitte/ch/Documents/manufacturing/ch-en-manufacturing-industry-4-0-24102014.pdf.

Dumitrescu R., Gausemeier J., Kühn A., Luckey M., Plass C., Schneider M. \& Westermann, T. (2015). Auf dem Weg zu Industrie 4.0: Erfolgsfaktor Referenzarchtiektur. it's OWL Clustermanagement.

Erol, S., Jäger, A., Hold, P., Ott, K. \& Sihn, W. (2016). Tangible Industry 4.0: a scenario-based approach to learning for the future of production. Procedia CIRP, 54, 13-18.

EUROPEAN COMMISSION. (2021). Internal Market, Industry, Entrepreneurship and SMEs. https://ec.europa.eu/growth/sectors/automotive_en.

EUROPEAN COMMISSION. (2017a). Autonomous cars: a big opportunity for European industry. Digital Transformation. https://ec.europa.eu/growth/ tools-databases/dem/monitor/category/automotive

EUROPEAN COMMISSION. (2017b). Adoption of novel technologies across the automotive value chain. Digital Transformation Monitor. https://ec.europa.eu/growth/tools-databases/dem/monitor/content/adoption-novel-technologies-across-automative-value-chain.

FIRJAN. Federação das Indústrias do Estado do Rio de Janeiro (2016). Indústria 4.0: Panorama da Inovação. http://www.firjan.com.br/publicacões.

FIRJAN. Federação das Indústrias do Estado do Rio de Janeiro (2019). Industria 4.0 no Brasil: oportunidades, perspectivas e desafios. SENAI, Finep. Rio de Janeiro, s.n.

Folmer, E., Van Sinderen, M. \& Oude Luttighuis, P. (2014). Enterprise interoperability: information, services and processes for the interoperable economy and society. Inf Syst E-Bus Manage 12, 491-494.

Frank, Ag., Dalenogare, L.S. \& Ayala, N.F. (2019). Tecnologias da Indústria 4.0: padrões de implementação em empresas de manufatura. International Journal of Production Economics, 210, 15-26.

Geissbauer, R., Edsø, J. \& Schrauf, S. (2016). https://www.strategy-business.com/article/A-Strategists-Guide-to-Industry-4.0?gko=a2260.

Görçün, O. F. (2018). Industry 4.0. Beta Publisher, 1-199.

Hermann, M., Pentek, T., \& Otto, B. (2016). Design principles for industry 4.0 scenarios. System Sciences (HICSS), 49th Hawaii International Conference, 3928-3937.

Hirsch-Kreinsen, H. (2016). Digitalization of industrial work: Development paths and prospects. Journal for Labour Market Research, 1-14.

Ibarra, D., Ganzarain, J. \& Igartua, J.I. (2018). Business model innovation through Industry 4.0: a review. Procedia Manufacturing, 22 , 4-10.

IEDI. (2019). https://iedi.org.br/media/site/artigos/20190311 industria_do_futuro_no_brasil_e_no_mundo.pdf.

Kagermann, H. (2015) Change through digitization-value creation in the age of industry 4.0. Management of Permanent Change, $23-45$.

Kagermann, H., Wahlster, W. \& Helbig, J. (2013). Recommendations for Implementing the Strategic Initiative INDUSTRIE 4.0. Final report of the Industry $4.0 \mathrm{WG}$.

Kahn, K. B. \& Mentzer, J.T. (1996). Logistics and interdepartmental integration. International Journal of Physical Distribution and Logistics Management, $26,8,6-14$.

Khan, A. \& Turowski, K. (2016). A Perspective on Industry 4.0: From Challenges to Opportunities in Production Systems. In Proceedings of the International Conference on Internet of Things and Big Data (IoTBD).

Lee, J. D., Bagheri, B., \& Kao, H. A. (2015). A Cyber-Physical Systems architecture for Industry 4.0-based manufacturing systems. Manufacturing Letters, 3 , $18-23(2015)$

Liao, Y., Deschamps, F., Loures, E.D.F.R. \& Ramos, L.F.P. (2017). Past, present and future of Industry 4.0-a systematic literature review and research agenda proposal. International Journal of Production Research. 55, 12, 3609-3629.

Lorenz, M., Küpper, D.; Rüßmann, M., Heidemann, A. \& Bause, (2016). A. Time to Accelerate in the Race Toward Industry 4.0. Boston Consulting Group.

Lu, Y. (2017). Industry 4.0: a survey on technologies, applications and open research issues. Journal of Industrial Information Integration. 6, 1-10.

Macdougall, W. (2014). Industry 4.0 Smart Manufacturing for the Future. Germany Trade and Invest.

Mak, B., MF. Othman, NH. Nor \& MFT. Azli. (2016). Industry 4.0: A Review on Industrial Automation and Robotic. Jurnal Teknologi. Sciences \& Engineering. 
MDIC- Ministério da Economia, Indústria, Comércio e Serviços. Competitividade Industrial, Setor Automotivo. http://www.mdic.gov.br/index.php/ competitividade-industrial/setor-automotivo.

Moeuf, A., Pellerin, R., Lamouri, S., Tamayo-Giraldo, S. \& Barbaray, R. (2017). The industrial management of SMEs in the era of Industry 4.0. International Journal of Production Research, 56, 3, 1-19.

Nyaga, G.N., Whipple, J.M. \& Lynch, D.F. (2010). Examining supply chain relationships: do buyer and supplier perspectives on collaborative relationships differ? Journal of Operations Management, 28 2, 101

Pagell, M. (2004). Understanding the factors that enable and inhibit the integration of operations, purchasing and logistics. Journal of Operations Management, $22,5,459-87$.

Pilloni, V. (2018). How Data Will Transform Industrial Processes: Crowdsensing, Crowdsourcing and Big Data as Pillars of Industry 4.0. Future Internet.

Porter, Michael, \& Heppelmann, James E. (2014). How Smart, Connected Products Are Transforming Competition. Harvard Business Review, Brasil, 2014. https://hbrbr.com.br/como-produtos-inteligentes-e-conectados-estao-transformando-a-competicao.

PWC. (2016). https://www.pwc.com.br/pt/publicacoes/servicos/assets/consultoria -negocios /2016/pwc-industry-4-survey-16.pdf.

Rachinger, M., Rauter, R., M€uller, C., Vorraber, W. \& Schirgi, E. (2018). Digitalization and its influence on business model innovation. Journal of Manufacturing Technology Management.

Ras, E., Wild, F., Stahl, C. \& Baudet, A. (2017). Bridging the skills gap of workers in industry 4.0 by human performance augmentation tools: challenges and roadmap. Proceedings of the 10th International Conference on Pervasive Technologies Related to Assistive Environments, ACM, New York, 428-432.

Rüßmann, M., Lorenz, M., Gerbert, P., Waldner, M., Justus, J., Engel, P. and Harnisch., M. (2015). Industry 4.0: the future of productivity and growth in manufacturing industries. Boston Consulting Group, 9, 1, 54-89.

Schuh, G., Potente, T., Wesch-POtente C., Weber, A.R. \& Prote, J.P. (2014). Collaboration Mechanisms to increase Productivity in the Context of Industrie 4.0. Robust Manufacturing Conference (RoMaC 2014), Procedia CIRP 19, 51 - 56.

Schuh, G., Anderl, R., Gausemeier J., Ten Hompel, M. \& Wahlster, W. (2017). Industrie 4.0 Maturity Index. Managing the Digital Transformation of Companies. (Acatech Study), Munich: Herbert Utz Verlag.

Schwab, K. (2017). The Fourth Industrial Revolution, first ed. World Economic Forum

Soares Pereira, A., Moreira Shitsuka, D., Parreira, F. J., \& Shitsuka, R. (2018). Metodologia da Pesquisa Científica (1 e-bookth ed.). Santa Maria, RS : UFSM, NTE.

Strange, R. \& Zucchella, A. (2017). Industry 4.0, global value chains and international business. Multinational Business Review, 25,3 , $174-184$.

Tomas, R. N., \& Alcantara, R. L. C. (2013). Modelos para gestão de riscos em cadeias de suprimentos: revisão, análise e diretrizes para futuras pesquisas. Gestão da Produção., São Carlos, 20, 3.

VDI - Associação de engenheiros Brasil-Alemanha. (2020). https://www.vdibrasil.com.

Vogel-Heuser, B. \& Hess, D. (2016). Guest editorial industry 4.0 - prerequisites and visions. IEEE Trans. Autom. Sci. Eng. 13 (2), $411-413$.

Wang, L., Törngren, M. \& Onori, M. (2015). Current status and advancement of cyber-physical systems in manufacturing. Journal of Manufacturing Systems, 37 , October, 517-527.

Wang, S., Wan, J., Zhang, D., Li, D. \& Zhang, C. (2016a). Towards Smart Factory for Industry 4.0: A Self-organized Multi-agent System with Big Data Based Feedback and Coordination. Comput. Netw.

Wang, S., Wan, J., Li , D. \& Zhang, C. (2016 b). Implementing smart factory of industrie 4.0: an outlook. International Journal of Distributed Sensor Networks, 12,.1,3159805.

Wiengarten, F., Humphreys, P., Cao, G., Fynes, B. \& Mckittrick, A. (2010). Collaborative supply chain practices and performance: exploring the key role of information quality. Supply Chain Management: An International Journal, 15, 6, 463-73.

World Economic Forum. (2020). http://www3.weforum.org. Fourth Industrial Revolution: Beacons of Technology and Innovation in Manufacturing.

Zhong, R.Y., Xu, X., Klotz, E. \& Newman, S.T. (2017). Intelligent manufacturing in the context of Industry 4.0: a review. Engineering. 